\title{
Blockchain and Bitcoin: The Revolution of the Financial Industry
}

\author{
Saghrane Mohamed Yassine \\ $\mathrm{PhD}$ Student in Economics and Management fsjes Souissi \\ Alaoui Lalla Latifa \\ Professor at the fsjes Souissi \\ Benayache Sarah \\ $\mathrm{PhD}$ Student in Economics and Management fsjes Souissi \\ Research Team on Finance, Economic Policy and Enterprise \\ Competitiveness, FSJES - SOUISSI, Mohammed -V University Rabat \\ Morocco
}

Doi: 10.19044/elp.v4no4a1 URL:http://dx.doi.org/10.19044/elp.v4no4a1

\begin{abstract}
Bitcoin is a technology operating without a central authority. The management of the transaction and the creation of bitcoins constitute an assumption of responsibility collectively by the network. Bitcoin is free and open. Its design is public, nobody has nor controls this type of currency and any individual can purchase it. Thanks to several of its single properties, Bitcoin entails promising uses, which are not presently covered by the systems of classic payments. The digital currency bitcoin primarily relies on a type of technology referred to as blockchain and has several implications for the economy and corporations. Bitcoins are used everywhere in the world and can serve as a tool of decentralization and freedom. There is a significant number of companies and individuals who use Bitcoin, with certain organizations currently accepting it as a method of payment. Although Bitcoin remains a relatively new phenomenon, it has experienced a rapid growth. At the end of August 2017, the value of all the bitcoins in circulation exceeded 16.5 million bitcoin with millions of dollars exchanged daily in bitcoins (market cap 77 billion dollar). This paper will provide a brief outline of this subject, along with essential information on Blockchain and bitcoin. After providing a definition of the latter two, we will present their impact on the financial industry, and finally we will evaluate the function of the stock of value on the calculation of the volatility of the bitcoin by reporting it to gold and the EUR/USD parity.
\end{abstract}


Keywords: Bitcoin, blockchain, crypto currency, volatility, currency, value of stock.

\section{Introduction}

The blockchain (chain of blocks) is a technology, which makes it possible to store and transmit information in a transparent way, made safe and without a central body of control. It resembles a great database, which contains the history of all the exchanges conducted between its users since its creation. The blockchain can be used in three different ways: for transfer of credits (currency, titles, actions, etc.), for a better traceability of credits and products and to carry out contracts automatically ("smart contracts"). The great characteristic of the blockchain is its decentralized architecture, i.e. it is not lodged by a single waiter but by part of the users. There is no intermediary so that each user can check the validity of the chain individually. The information contained in the blocks (transactions, documents of title, contracts, etc.) is protected by cryptographic processes, which prevent the users from modifying them a posteriori. "The blockchain is an incorruptible digital ledger of economic transactions that can be programmed to record not just financial transactions but virtually everything of value." 2 The bitcoin was created in 2008 by Satoshi Nakamoto, the nickname that a person was given to remain anonymous to date, and who developed the code of the currency and whose true identity remains a mystery. Bitcoin is virtual money on a computer network peer to peer or decentralized based on the principles of cryptography to validate the transactions. Currently, Bitcoin is regarded as alternative currency, because it does not have a legal tender in any country. It does not have a physical support, and it is useful in the transactions online or with the tradesmen who accept them. The transactions of Bitcoin in the real shops take usually the shape of mobile payments using purse electronic. There exist a hundred crypto-currencies, several standards, but the bitcoin is worth expensive than an ounce of gold, a rise which could continue well (at the $9 / 8 / 2017,1 \mathrm{btc}=4259 \$ / 3538 €)^{3}$. Certain platforms give the opportunity of converting Bitcoin into dollars, euro or yuan. It is the case of Paymium ${ }^{4}$ who

\footnotetext{
1 Blockchain : definition and application of techno behind the bitcoin, La Rédaction, JDN, http://www.journaldunet.com/economie/finance/1195520-blockchain/

2 Don \& Alex Tapscott, authors Blockchain Revolution (2016)

3 https://bitcoin.fr/cours-du-bitcoin/

4 Created in 2011, the Paymium French company is pionnier of the Bitcoin services, with several tens of thousands of European consumers. The platform of bitcoin exchange/Paymium.com Euro, is the first European place on the market offering a service in accordance with the European regulation on the services of payment. Paymium also suggests solutions for the tradesmen and the processors of payments enabling them to accept the payments in bitcoins, while being freed from the exchange rate risks and by reducing the expenses of transaction.
} 
allows exchanging bitcoin against euro. The bitcoin has a course very volatile. This volatility is related on the strong speculation around this currency and the absence of a regulating authority. On August 13th, 2017, the course of the bitcoin exceeded for the first time the 4000 dollars, and its value practically doubled in a few months. Its capitalization has as for it reaches 77 billion dollars in the month of September 2017. In this research one presents an outline of the subject to you, you will know the necessary one to what you need to know about Blockchain and the bitcoin. After the definition of these two last, we will present their impacts on financial industry, and in the last we will evaluate the function of the stock of value on the calculation of volatility. Our methodology of work is based on longitudinal studies of the observation and the evolution of the volatility of the bitcoin compared to gold and parity EUR/USD.

\section{The chain of block or the blockchain}

\subsection{Definition and history}

The blockchain is a technology of storage and transmission of information, transparent, made safe, and functioning without central body of control. The blockchain, or chains blocks, is indissociable bitcoin. By extension, a blockchain constitutes a database which contains the history of all the exchanges carried out between its users since his creation. This database is made safe and distributed: it is shared by its various users, without intermediary, which makes it possible each one to check the validity of the chain. There exist public blockchains, open to all, and deprived blockchain, of which the accesses and the use are limited to a certain number of actors. A public blockchain can be comparable with a large public, and his is anonymous and like a book countable how can be not falsified. Like writes it the mathematician Jean-Paul Delahaye, it is necessary to think « a very large book, that everyone can read freely and free, on which everyone can write, but which is impossible to delete and indestructible. $\rangle^{5}$ The operation of the blockchain is founded on control by the majority, primarily, it is right an entry of digital operations, shared between multiple recipients. It can be updated only by consensus between majorities of participants in the system. And, once entered, information can never be crushed. Thus, the blockchain of the bitcoin contains an unquestionable and verifiable recording of the least transaction bitcoin ever realized. ${ }^{6}$ The headlight application of this technology is that of the cryptocurrencies like the east for example the bitcoin, which is however far from

\footnotetext{
5 https://blockchainfrance.net

6 Translation and adaptation of the following article, written by Mike Gault (fondateur et PDG de Guardtime) : http://recode.net/2015/07/05/forget-bitcoin-what-is-the-blockchainand-why-should-you-care/.
} 
being the only virtual currency ${ }^{7}$ : here are different multiples like ether of the blockchain Ethereum. Beyond its monetary aspect, this technology of decentralized storage of information could have multiple applications, of which:

- Applications known as « Bitcoin $2.0 »^{8}$;

- Applications based on the intelligent contracts, allowing to exchange all kinds of goods or services ${ }^{9}$;

- Means of reducing the costs of payment and the costs of transaction.

The international banks made announcements in 2015 on these subjects. Twenty-five of them for example signed a partnership with a R3 US company for the use of blockchain in the financial markets ${ }^{10}$. Citibank also announced its wish to emit its clean crypto currency, Citicoin ${ }^{11}$. In the same way, in April 2015, the UBS bank opened in London its own research laboratory dedicated under investigation of technology blockchain and with its applications in the financial field ${ }^{12}$. Through this research and these consortia, the banks hope to set up a technology based on the blockchain which will become a reference within the banking field. Indeed, the consortium or the bank which will manage the first to leave a tested technology will be capable to invoice its own service near the other actors of the financial field ${ }^{13}$;

- Means of improving their predictive systems known as "of oracles", for the insurances in particular ${ }^{14}$;

- The development of insurances peer-to-peers ${ }^{15}$.

\subsection{Electronic wallet or bitcoin wallet}

[A wallet of Bitcoin is software where Bitcoin are stored. To be technically precise, Bitcoin are not stored anywhere; there is a key deprived

7James Temperton, "Bitcoin might fail drank the blockchain is young stag to stay" [files], November 24th, 2014 (consulted on October 26th, 2015).

8 Dominic Frisby, "The Incredible Technology Behind Bitcoin Is About To Change The World" [files], Insider Business, January 21st, 2015 (consulted on October 26th, 2015) 9 Smart Contracts: The Next Big Blockchain Application "[files], Cornell Tech (on June 6th, 2016)

10 "Nine of world' S biggest banks join to forms blockchain partnership", Reuters, September 15th, 2015 (to read online [archive])

11 John Biggs, "Citibank Is Working One Its Own DIGITAL Currency, Citicoin" [files] (consulted on November 20th, 2015)

12 "UBS works with a universal currency based on technology blockchain - ICTjournal" [files], on www.ictjournal.ch (consulted on June 6th, 2016)

13 "The secret battle of the banks to lay hands on the blockchain" [files], on www.journaldunet.com (consulted on June 9th, 2016)

14 Etherum and Oracles [archive].

15 "Insurance distributed and smart contracts" [files], on Blockchain France (consulted on March 8th, 2016). 
for each address of Bitcoin which is recorded in the wallet of Bitcoin of the person who has balance. The wallets of Bitcoin facilitate to send and receive Bitcoin and give the property of the balance of Bitcoin to the user. The wallet of Bitcoin comes under many forms; the office, the mobile, the Web and equipment are the four principal types of wallets breaking up the 'wallet of Bitcoin. A wallet of Bitcoin also indicated under the name of a digital wallet. The establishment of such a wallet is a big step in the course of obtaining Bitcoin. Just as Bitcoin are the digital equivalent of cash, a wallet of Bitcoin is similar in a physical wallet. But instead of storing Bitcoin literally, which is stored is much important information like the sure private key used to reach at addresses of Bitcoin and to carry out transactions. The four principal types of wallet are:

- Wallets of office are installed on a desktop and provides to the user complete control above wallet. The wallets of office make it possible to the user to create an address of Bitcoin to send and receive Bitcoins;

- The mobile wallets overcome the handicap of the wallets of office, because this last are fixed in a place. Once you to download the application on your smartphone, the wallet can carry out the same functions like wallet of office, and helps you to directly pay your mobile of anywhere. Thus a mobile wallet facilitates by carrying out payments in the physical stores using the "contact-with-wages" via $\mathrm{NFC}^{16}$ sweeping a code of QR ${ }^{17}$.

- The wallet of Bitcoin, the Android hive and the wallet of Bitcoin of mycelium are little mobile wallets.

- Wallets of Web, they enable you to employ Bitcoin of anywhere, on any browser or mobile. Coinbase and Blockchain are the popular suppliers of wallet of Web. $]^{18}$

16 NFC, or Near Field Communication, is a technology still recent and called to spread on all the wandering devices in the years to come. One can affirm without too many risks to be mistaken that the NFC will be in the long term implemented by default on all our smartphones, connected shelves, audio-video readers, as well as Bluetooth or Wifi for example.

17 QR code is the acronym of Quick Answer Codes or code bar 2D. Whereas the classical code bar allows only one horizontal coding, the QR code is in two dimensions and thus understands more information. The QR code is a tag readable by the mobile phones and shelves. Its use makes it possible to give access to audio or video contents, to take part in a quiz or to even carry out a purchase starting from its mobile phone, Written by B.Bathelot, updated on December 17th, 2015. Glossaries: Mobile marketing.

18 Translation and adaptation of the following article, Bitcoin Wallet, http://www.investopedia.com/terms/b/bitcoin-wallet.asp 


\section{Bitcoin, electronic system of payment}

\subsection{Definition and history}

The bitcoin is a virtual currency (or crypto-currency) created in 2009 by one or more data-processing programmers using the pseudonym "Satoshi Nakamoto". The bitcoin is exchanged of par with par (particular or company) on Internet against of other monetary currencies (euro, dollar, yen...), inoutside classical banking networks. And it is accepted like means by certain physical tradesmen and online. The bitcoin is deprived of legal framework unlike other monetary currencies:

- The bitcoin does not have a legal tender;

- Its value is not controlled by a central bank (the European Central bank for the euro or American Federal reserve concerning the dollar).

[The trade on Internet depends today almost exclusively on financial institutions which are used as third of confidence to treat the electronic payments. Although this system functions rather well for most transactions, it always bails out weaknesses inherent in its model based on confidence. The completely irreversible transactions are not really possible there, since the financial institutions must manage the mediation of conflicts. The cost of this mediation increases the costs of the transactions, limiting in practice the minimal size of a transaction and preventing the possibility of having small inexpensive transactions. Impossibility of having nonreversible payments for nonreversible services generates a cost even more important. With the possibility of reversing the transactions, the need for confidence increases. The merchants must be wary of their customers, by badgering them to obtain more information than necessary. A certain share of frauds is accepted like inevitable. All these costs and uncertainties of payment can be avoided by the use of a physical currency, but no mechanism exists to carry out payments through a communication system without resorting to a third of confidence. $]^{19}$ On March 2017, the bitcoin exceeded the rate of gold. This is the proof that the virtual currency gains of credibility compared to a yellow metal sounding and stumbling. A bitcoin reached its higher history on May 24th with 2791 dollars in May, while the course of the ounce of gold was established with 1262 dollars. At the end of the month of August 2017, the value of all bitcoins ${ }^{20}$ in circulation exceeded 16.5 million bitcoin with million dollars exchanged daily in bitcoins, its market capitalization reached 77 billion dollar). In month of September 2017 the value of the bitcoin was established with the turn of 4259 dollars against 3538 euros.

19 Bitcoin: System of Plastic money in Par-with-Par. Satoshi Nakamoto - satoshin@gmx.com - www.bitcoin.org (Translators: Benkebab, Grondilu, Mackila)

20 https://blockchain.info/fr/charts/total-bitcoins 


\subsection{Bitcoin and store of value money function}

[The functions of the money are generally distinguished and allowed. There is only difference of how much functions the money are distinguished. Jevons in its book starting from 1875 "money and the mechanism of the exchange" defines four basic money functions: Monetary agent, united action of value, level of value and stock of value. In the current money theory other money functions occur like the function of information, the function of investment, etc (Jedlinský 2014, P. 49-51). Need to identify the stock of the money function of express Jevons value with the following argument: "But sometimes a person must condense her property in the smallest compass, so that it can pile up it far during a certain time, or relates it with him to a long journey, or communicate it to a friend in a distant country. "(Jevons, 2011, P. 22) obviously we have improve the possibilities how to communicate the property with a friend in a distant country and the use of Bitcoin is one of them. But the need for storing the property is part leaves essential economy. People must cope with the fact that their incomes change in time and pile up a certain amount of money in good periods during futures bad moments possible. To buy goods which are more expensive than the regular wages the function of the storage of value implies. A contrary argument against the stock of value is made for example by Graham (Graham, 1940) which recognizes only two primary functions of money: money like unit of accounting and money like carrier of the options. All other functions are derived from these primary functions. Graham declared that "many of other things, easy to store, easy to move, provide a substitute more than acceptable for the money in this respect." (Graham, 1940, P. 2) it does not mean that Graham countermanded the stock of function of value of the whole, the need to hold the money remains, but is explained as participation provisional and included under the carrier of the function of option] $]^{21}$.

The defenders of Bitcoin criticize fiduciary currencies for their character of inflation. According to the opinion of the defenders of Bitcoin, the store of the function of value is not achieved by fiduciary currencies and in this function the virtual currencies are competing. There is also the argument that the whole success of the virtual currencies is based on the fact of its not-inflation. ${ }^{22}$

21 Translation and adaptation of the following article, Virtual currency bitcoin in the scope of money definition and blind of been worth, Max Kubát, University of Economics, Winston Churchill sq. 4, Prague 130 67, Czech Republic, pages 413.

22 Translation and adaptation of the following article, Virtual currency bitcoin in the scope of money definition and blind of been worth, Max Kubát, University of Economics, Winston Churchill sq. 4, Prague 130 67, Czech Republic, pages 414. 


\section{Impact and limit of blockchain technology}

The blockchain is a great public countable work (database) where the exchanges are protected and diffused near the community in order to be validated out of economic system.

The idea of chain of blocks or Blockchain is a technique of cryptography and a tool of indexation of the "Proof of Work" or POW) ${ }^{23}$ who of its own person is based on the tool of Hash cash provides by Adam Back in 1997... 20 years ago. In short and according to us, it is not the technique blockchain in itself which is innovating, but makes of them the evolutions with use, the principles of equipment and services carried by new actors and more precisely in the banking environments and of the insurances.

\subsection{Impact blockchain on financial industry}

The current financial system is based on the idea of confidence. The banks treat into same time, most of the time via a room of regulation and compensation which has like objective to make reduce the dangers from counterpart by guaranteeing the regulation-delivery of the transactions. According to the opinion of the financial institution, as an organization, some monitoring system, of execution and reconciliation authorize to be on that good progress of the events. One frequently speaks about work of back-office which is usually perceived like centers price for the financial institution. [The collaborative economy functions through a decentralized mode of production (generally via a platform), without intermediary or hierarchical supervision. One understands thus that the blockchain is adapted perfectly to this model. Indeed, the decentralization is in the middle of technology blockchain. Thus, it would seem that the blockchain offer all the tools which the collaborative economy needs: software open-source, data protection, secure management of rights and licenses, etc It is about empower to the maximum the individuals through the computer tools, in order to make them able to carry out transactions without the assistance of a central institution. The principle even of the blockchain is to replace the "thirds of confidence" by distributed computer software, thus the scopes of application are almost unlimited: transport, health, entertainment, and well of others. The blockchain, explains Benjamin Tincq, co-founder of OuiShare ${ }^{24}$, « it falls under a major change of our companies which seek to transform our organizational systems (...) and to break with pyramidal logics and the very centralization of the value». One finds in the blockchain logic of collaboration since the users take part jointly

23 http://www.hashcash.org/papers/announce.txt

24 OuiShare is an ONG founded in January 2012 in Paris, which is presented in the form of "a community, an accelerator of ideas and projects dedicated to the emergence of the collaborative company: a society based on principles of opening, collaboration, confidence and division of the value". Source: Wikipedia 
in the development of the system and the system remunerates them for their work. Thus the blockchain seems to satisfy the concepts of reciprocity, community and participative financing, expensive with the collaborative economy. $]^{25}$ The blockchain guaranteed of the substantial economies for the company's financial from a point of view of price-cutting associated with the infrastructure for management with the world money sending, the negotiation of titles and the insurance of conformity with the regulations. That is recovered in the recent analysis of the Santander financial institution ${ }^{26}$ who estimates economies with the neighborhoods from 15 to 20 billion each year by 2022 . Swiss banking institution UBS ${ }^{27}$ estimate for their part that the programs of the blockchain would make it possible to lower the times of the world money sending. In the insurance, the actors, usually attentive against the disruptive techniques, also look in the blockchain of opportunities to increase the combat controls the cheating by a faster and more transparent access to information in more automated way. The management of the layouts of expert testimony is improved by the fact that the same sale once carried out is shared and published on the totality of the infrastructure, which does not authorize any change or defrauds.

\subsection{Challenges and limits of Blockchain technology}

[The technology of blockchain is surely an innovating technology which has various scopes of application. In spite as of potential occasions, one notes that the technology of blockchain is not a universal solution which will solve all the related questions of corruption that we cope. Without considering the questions of government and intimacy of data, its application about the chain of supplies can lead to a twisted structure of the market and cause a new type of corruption] ${ }^{28}$. [Even with these innovating characteristics, the technique blockchain does not go without raising certain notable difficulties. Latency of treatment: the blockchain is based on the infrastructure of nodes to approve the exchanges, an operation which takes eight minutes overall. In such a current situation, the heaviness of these controls slows down the approval of this technique, in spite of its modern character. A lawful lack of framing: the even tool with par given appears not to leave any place to a

25 Oriane TROUGH, Aude CLERK, Meyssane FAKIRL' collaborative economy: first steps of a major recasting of the economic systems towards a total desintermediation by the blockchain? Project of end of studies EMLYON December 2016, pages 46

26http://santanderinnoventures.com/wp-content/uploads/2015/06/The-Fintech-2-0-Paper.pdf 27 https://www.ubs.com/global/en/about_ubs/follow_ubs/highlights/davos-2016.html

28 Kibum Kim, Consultant at KPMG, Seoul, Korea, Taewon Kang, Ph.D Candidate at Seoul National University, Seoul, Korea Does Technology Against Corruption Always Lead to Benefit? The Potential Risks and Challenges of the Blockchain Technology, 2017, pages 12 et 15 
supervisory body. The law and the laws are with collects, leaving open the interrogation of an operation without legal framework. Deficit of qualities methods: in very undertaken, a novel method can sow the imbroglio in the spirit of the people who are in stage of training. Incompatibility with the computer systems which exist: this technology claims deep modifications in the systems which exist and of the placements raised at the moment of the transition. Control, security and confidentiality: even if the blockchain calls on cryptographic methods progress, the pooling of the accounts books of the exchanges can however develop indiscretions of explanations and threaten the confidentiality. ${ }^{29}$ The blockchain affects all the lawful while agreeing by anonymous people or organizations and decentralized market. This recent innovation is likely to involve, with final, of the material changes on the strategy of the sovereignty of the State.

\section{Statistical data analyses of Bitcoin through the blockchain}

\subsection{Market capitalization and trade volumes in USD}

Figure 1: Market capitalization of Bitcoin

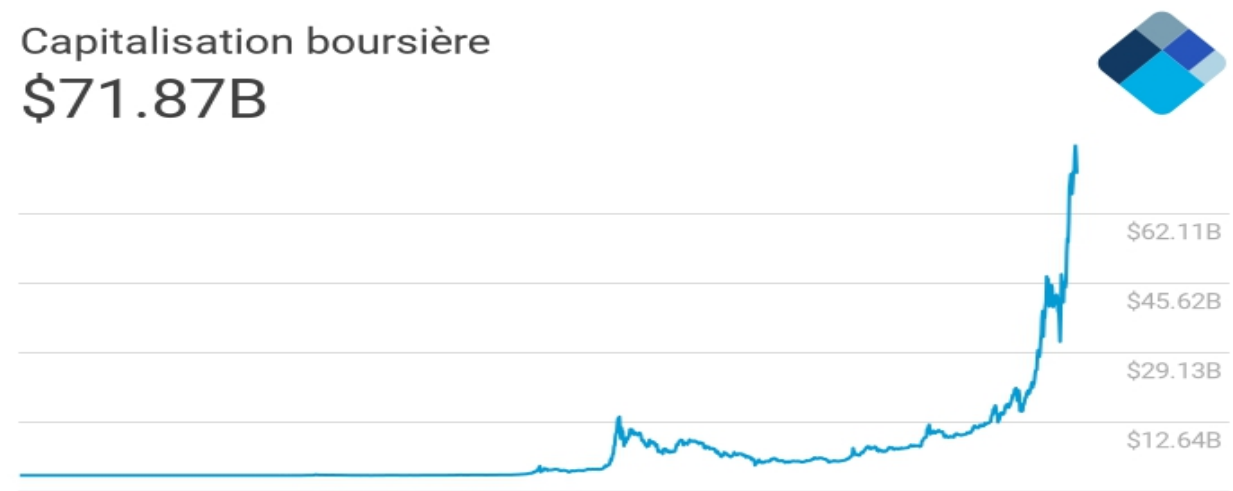

2009-01-03

blockchain.info/charts

2017-09-04

\section{*Source: https://blockchain.info/charts}

The market capitalization of the bitcoin knew one year very animated, in January 2017 it was approximately 16 billion dollar, after eight month and four days it could reach 71.87 billion dollars, that is to say an increase of 55.87 billion dollar.

29 The blockchain: opportunities, advantages and limits July 2017 by Serge Niango, Directing Before-Sale France, Citrix, www.globalsecuritymag.fr/La-blockchainopportunites,20170710,72521.html 
Figure 2: Volumes of exchanges in USD

Volume des échanges en USD

$\$ 467,133,132.49$
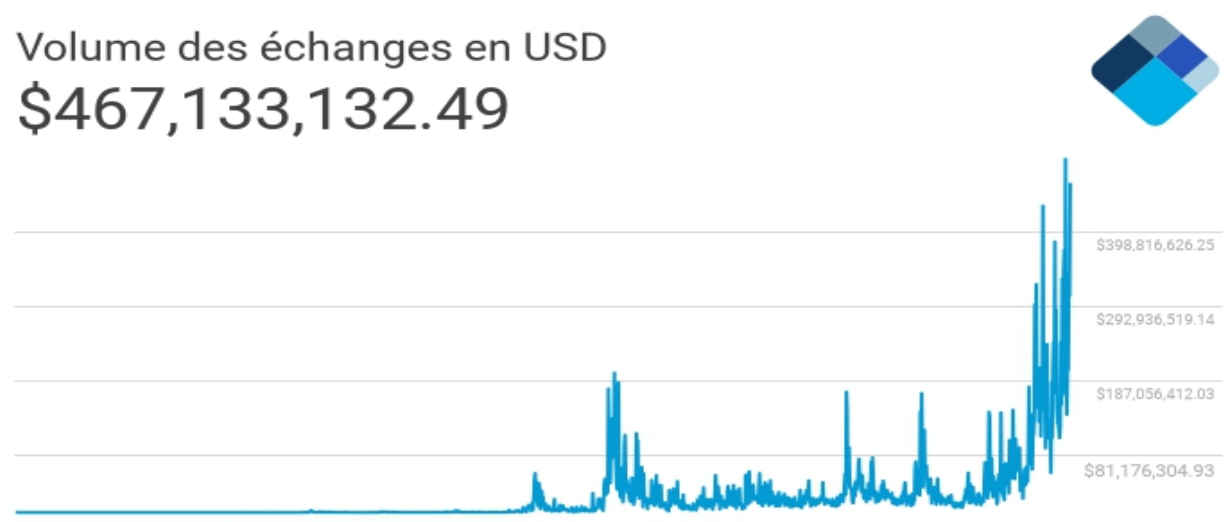

\section{*Source: https://blockchain.info/charts}

Volumes of exchanges in USD at the beginning of the year was approximately 33.9 million dollars, the 9/5/2017 this last knew a very important reversal, the total volume of the transactions reached 467.1 million dollars is an increase of 433.2 million dollars.

\subsection{Bitcoin in circulation and Market prices in USD}

\section{Figure 3: Bitcoin in circulation}

Total des bitcoins en circulation

$16,546,850.00$ BTC

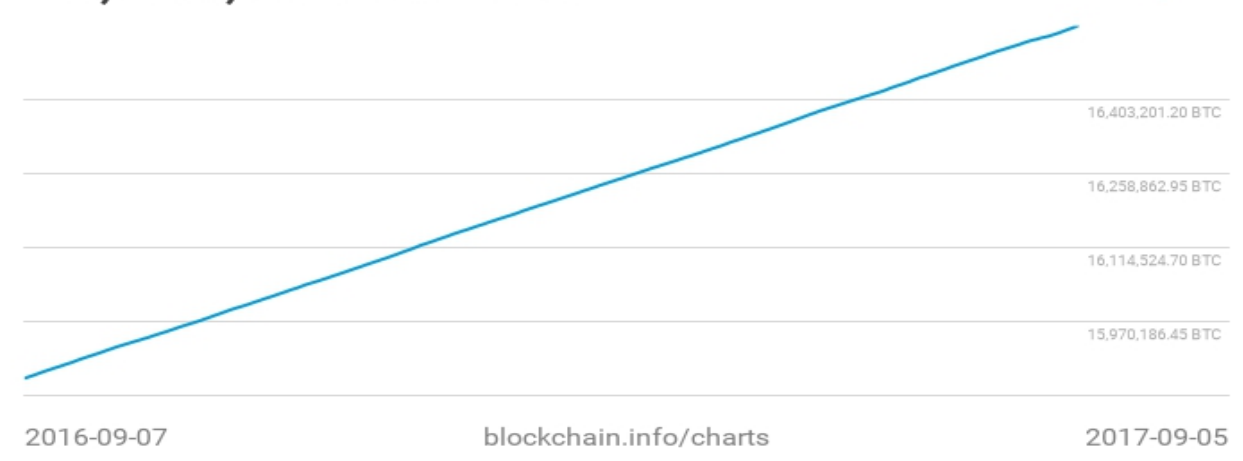

*Source: $\underline{\text { https://blockchain.info/charts }}$ 
Figure 4: Evolution number of Bitcoin in circulation (2009-2017)

\begin{tabular}{|l|l|}
\hline Date & Number of Bitcoin \\
\hline $3 / 01 / 2009$ & 50 \\
\hline $2 / 01 / 2010$ & 1635850 \\
\hline $5 / 01 / 2011$ & 5059050 \\
\hline $4 / 01 / 2012$ & 8030900 \\
\hline $4 / 01 / 2013$ & 10628700 \\
\hline $1 / 01 / 2014$ & 12203800 \\
\hline $2 / 01 / 2015$ & 13678725 \\
\hline $1 / 01 / 2016$ & 15031975 \\
\hline $5 / 09 / 2017$ & 16546850 \\
\hline
\end{tabular}

*Source: The figures come from the site blockchain.info/charts.

Figure 5 Market prices in USD

Le prix de marché (USD)

$\$ 4,344.09$

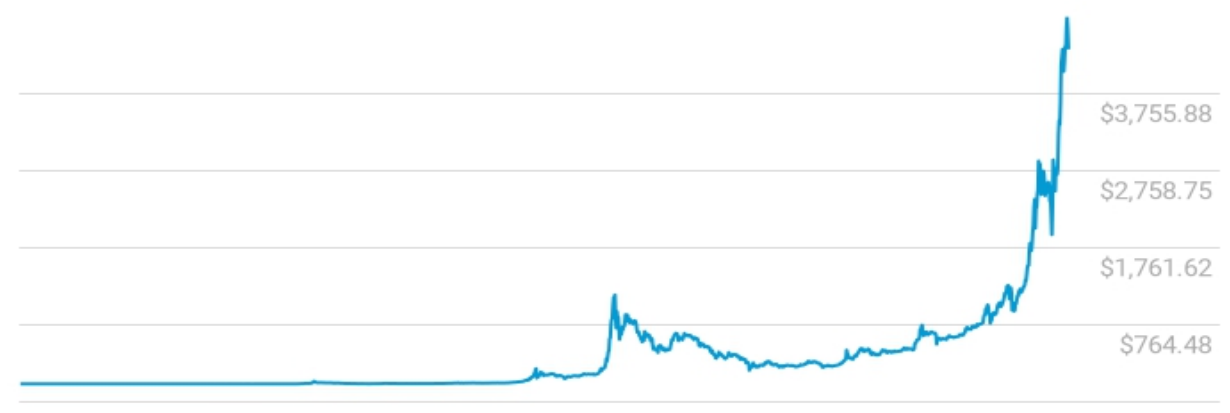

*Source: https://blockchain.info/charts

From a course of 20 USD recorded in January 2013, Bitcoin was registered quickly and continuously upwards, until reaching 266 USD on April 10th, 2013, in 2014 the price of the BTC passed to 312.71 USD, in 2015 its value reached 431.26 USD. In 2016 a unit BTC was equal to 969.53, thus spending the 9/4/2017 with 4344.09 USD. The forecasts concerning the evolution of the course of the bitcoin remain to complicate, as long as its market is very volatile. For certain analysts the course of the BTC could reach 5000 dollars before the end of the end of the year 2017. This volatility is related to factors of the economic situation such that certain currencies break down it, and the risks of geopolitical tensions all around the world. 


\section{Empirical study of Historical Volatility BTC, OR and EUR-USD}

\subsection{Methodology}

The bitcoin is not employed in a certain country where the citizens could mainly gain to save bitcoin and finally to buy goods. In this research we will evaluate the function of the stock of value on the calculation of volatility. Volatility can express the probability which it value of a unit of bitcoin or some capital remains stable in the course of time.

Volatility is volatility historical calculated according to the following formula:

The variance VAR is calculated in the following way: VAR= $\frac{1}{\mathrm{n}-1} * \sum_{\mathrm{i}-1}^{\mathrm{n}}(\mathrm{Ri}-\mathrm{m})^{2}$

Volatility VOL is calculated starting from the variance: VOL $=\sqrt{ }$ var

The base of calculation of volatility is calculated is spread out over four years and precisely since 2014. This period of time is justified as period of time when Bitcoin became more known by the public. In this study we go compared the results calculated with the volatility of gold. On March 2nd, 2017, the value of Bitcoin, for the first time, exceeded that of one ounce gold $^{30}$ $(1 \mathrm{BTC}=1257,6 / \mathrm{XAU}=1235,02)^{31}$ who is often regarded as capital representing the ideal money for everyone which does not like the fiduciary currency and the value of the intrinsic money does not underline. Fiduciary currencies should be also included with the comparison as a true competitor of the virtual currencies. I decided to choose parity EUR-USD. The euro is selected as important currency of the world which had much the problem these last years. The prices (exchange rate) are express in USD. Our methodology of research rests on longitudinal studies based on the observation of the trend of the price bitcoin, that of the gold and the parity EUR-USD.

\subsection{Result}

Figure 6: Table Historical Volatility BTC, GOLD and EUR-USD

\begin{tabular}{|c|c|c|c|c|}
\hline & 2014 & 2015 & 2016 & 2017 \\
\hline GOLD (XAU) & $24,76 \%$ & $19,46 \%$ & $15,74 \%$ & $12,09 \%$ \\
\hline BITCOIN (BTC) & $224,20 \%$ & $84,67 \%$ & $40,70 \%$ & $122,22 \%$ \\
\hline EUR-USD & $10,00 \%$ & $17,98 \%$ & $10,41 \%$ & $8,24 \%$ \\
\hline
\end{tabular}

*Source: work out by our own care

30 Comparison and followed by the trend of the price of the BITCOIN compared to that of gold while basing itself on the daily courses of the period 2009-2017.

31 www.abcbourse.com 
Figure 7: Chart of Historical volatility BTC, GOLD and EUR-USD

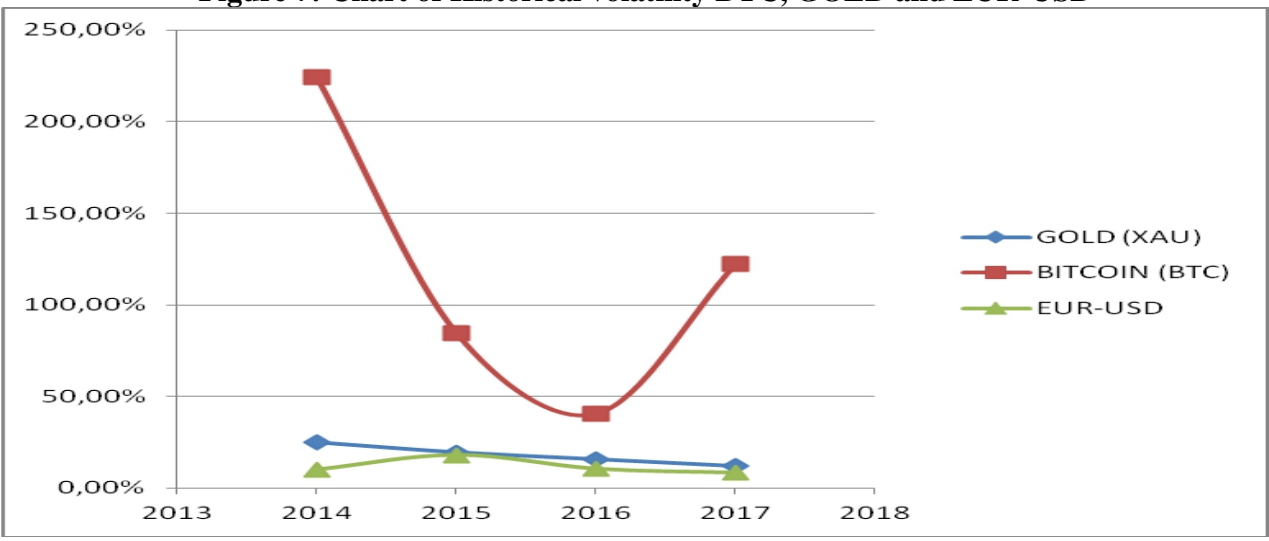

*Source: work out by our own care

\section{Interpretation and discussion:}

Lowest volatility is reached by parity EUR-USD. The average is of $11.66 \%$ in the four years end, and in 2017 it fell from approximately $2.17 \%$ compared to the previous year (VOL $2016=10,41 \%$ ) the currency shows the lowest volatility of the sample. Perhaps it is little of not very astonishing that the volatility of the currencies is lower than the volatility of gold $\mathrm{XAU}^{32}$, generally considered as sure capital. However, the gold volatility is very close to the volatility of currencies. In addition the volatility of the bitcoins is appreciably higher implying than the property of catch in this system is riskier.

The volatility of the BTC in 2014 was of $224.20 \%$, the year 2015 was difficult for the users of Bitcoin because of his regression about $-74.67 \%$. Similar for the year the 2016 volatility of the bitcoin relapsed of approximately $-43.97 \%$. These two years successive Crash can also have more classical explanations. It is possible that an actor holding a great quantity of Bitcoin wished to handle the course by selling a share of his wallet to cause the fall of the course, and to repurchase at better price. It can also to act of escape of a certain number of speculators, which massively resells their Bitcoins, which could be the sign of disillusion, after the euphoria: it was a time when Bitcoin was exchanged for a small thousand of euro. ${ }^{33}$ On the other hand the year 2017 was very promising for the bitcoin, its volatility increased (approximately $81.52 \%$ to $122.22 \%$ ) in one eight month period and some day. The exchange rate of Bitcoin, digital currency created in 2009, is shown especially dynamic at this beginning of year (2017). Why bitcoin is such a phenomenon of Russian mountain? The monetary economic recession in India

$32 \mathrm{XAU}$ is a code, which means: the code for the quotation of one ounce gold on the financial markets, according to the standard ISO 4217

33 Numerama magazine, Fall of Bitcoin: possible explanations, Julien Lausson 1/14/2015 http://www.numerama.com/magazine/31867-chute-bitcoin.html Business 
and the strategy of exchange control in China make bitcoin a species of specific currency refuge, without forgetting that $90 \%$ of the transactions on the sector of Bitcoin come from China. ${ }^{34}$ Even, if the bitcoin is very volatile, there remains regarded as a currency which meets a growing success. Can we consider the bitcoin as a good currency? Which is the impact of the bitcoin on the economy? Could the bitcoin become currency? The $5 / 25 / 2017$, one btc is equal to $2450.29 \$ / 2083.74 €$, today 1 btc is worth $4631 \$ / 3836 €$ an increase of $47.09 \%$ for the Dollars and a rise of $45.68 \%$ compared to the Euro.

\section{Conclusion}

The bitcoin became popular; it is paramount to start to have doubts about its use in illegal transactions, because of anonymity which it gives to its users. The criminal activities connected to the bitcoin exist, but they are rare. It is not the perfect currency of the crime because it is easily track, when the amount of the transactions exceeds the standard. It is necessary to also note that the companies which offer platforms of exchange must, like any platform of exchange of currency Forex ${ }^{35}$, must know their customers and thus carry out the procedures of $\mathrm{KYC}^{36}$. It is possible that the bitcoin is used as means of tax avoidance, today, the fact of buying bitcoins, that can be as to buy gold ingots which one would store without having them to declare with the tax department, draws that the virtual currency does not pose any problem of storage and makes it possible to remain no identifiable thanks to anonymity. Because of their particular (extraterritoriality and absence of organization of regulation) and of their operating process, the currencies digital present risks, which gives the possibility of financing criminal activities and to facilitate the bleaching of the latter. The appearance of new activities in link with the currencies digital asks the question of adaptation, and evolution of the legislative framework and lawful, particularly in terms of fight against the bleaching and the financing of terrorism, and the risks of use illicit ends of the currencies digital. For many analysts, the future of the bitcoin is far from being limited, in particular because its success is very correlated with the world events (like political uncertainties in the United States, the weakness of the growth in China or the elevated level of the debt in the countries of the

\footnotetext{
34 ZDNet.fr > News > Bitcoin: reasons of a very volatile course By Guillaume Serries $1 / 6 / 2017$

35 Forex is the abbreviation of FOreign and EXchange which indicates the worldwide market of the currencies, i.e. the market on which exchanges the currencies of the whole world. The FOREX represents in term of total volume, the second financial market of planet behind that of interest rates.

36 Know your customer (KYC) is the name given to the process allowing to check the identity of the customers of a company. The term is also used to refer to the banking regulation which governs these activities.
} 
European Union). In addition, from a legal point of view, an increasing interest goes on the search for a legal definition of the bitcoin in many countries. The interest of a definition and attribution of a legal framework proves a certain confidence and a way of controlling this special currency. The financial world is interested in this financial innovation, by observing its character of diversification and performance. The bitcoin was thus indicated like the most powerful credit of the year 2016 by boursier.com. The Blockchain technique is an information system which gives the possibility of recording exchanges which are filed there in a permanent way. This public channel is accessible to people, and the integrity of information. The totality of the members of the infrastructure has the whole of information. The blockchain is upgrade by the members, which at any moment gives the possibility of having an effective warning, when a new sale is emitted on a public blockchain. It is subordinated to a stage of validation called the "mining", carried out by a "minor". The objectives of the blockchain are innumerable and depend on the use of this one. The fundamental goal is to do without the intermediary. This is especially true for the economic market, where one can ultimately do without the financial institution to approve a financial sale.

\section{References:}

Ametrano, F.M [2014] "Hayek Money: The Cryptocurrency Price Stability Solution", http://papers.ssrn.com/sol3/papers.cfm?abstract_id=2425270;

Bank of England (2014 Q3), Ali R., of the Bank' S Financial Market Directorate Infrastructure, Barrdear J., of the Bank' S Monetary Assessment and Strategy Division, and Clews R. and Southgate J., of the Bank' S Markets Directorate, "Innovations in payment technologies and the emergence of digital currencies";

Davidson, L., W.E. Block [2015], "Bitcoin, the Theorem Regression, and the Emergence of has New Medium of Exchange", the Quarterly Newspaper of Austrian Economics, vol. 18, n 3, pp. 311-338

Decker, C, Wattenhofer, R. Information propagation in the bitcoin network. In: Proocedings of the International IEEE Conference one Peer-to-Peer Computing (P2P). 2013;

Dominic Frisby, "The Incredible Technology behind Bitcoin Is about to Change the World" [files], Insider Business, January 21st, 2015;

Dupre, D., J. - F. Ponsot J. - M. Servet [2015], the bitcoin against the revolution of the commun runs, communication to the 5th congress of the French Association of political economy, Lyon, July; HEEKS R., "Understanding "Gold Farming" and Real-Money Trading ace the Intersection of Real and Virtual Economies", Newspaper of Virtual Worlds Research, Vol.2 nº 4, February 2010; 
Herlin P. (2013), "the revolution in the currencies: to circumvent the banks and the States", in the Revolution of Bitcoin and the complementary currencies: A solution to escape from the banking system and the euro, Eyrolles Editions and Atlantis, 2013, pp. 32-40;

Kibum Kim, Consultant At KPMG, Seoul, Korea, Taewon Kang, Ph.D Candidate At Seoul University National, Seoul, Korea Does Technology Against Corruption Always Lead to Benefit? The Potential Risks and Challenges of the Blockchain Technology, 2017, pages 12 and 15;

Maftei, L. (2014), BitCoin - between legal and informal, THESE Working Papers, Vol.6, No.3, pp. 53-59;

THANKACHEN J., "Deep Web: Proverbial the Safe House for Cybercriminals", Wired, August 22nd;

The 'Great Bitcoin Exodus' has totally changed New York' S bitcoin ecosystem, New York Business Newspaper by Michael Del Castillo, the $8 / 12 / 2015$. 